\title{
Adapting to children's individual language proficiency: An observational study of preschool teacher talk addressing monolinguals and children learning English as an additional language
}

\author{
Kin Chung Jacky CHAN $^{1, \star}$ (D), Padraic MONAGHAN ${ }^{1,2}$ and Marije MICHEL $L^{1,3}$ \\ ${ }^{1}$ Lancaster University, UK \\ ${ }^{2}$ University of Amsterdam, The Netherlands \\ ${ }^{3}$ University of Groningen, The Netherlands \\ ${ }^{*}$ Corresponding author: Kin Chung Jacky Chan, Department of Psychology, Lancaster University, Lancaster \\ LA1 4YF, UK. Email: k.c.chan@lancaster.ac.uk
}

(Received 11 April 2020; revised 15 September 2021; accepted 03 December 2021)

\begin{abstract}
In an increasingly diverse society, young children are likely to speak different first languages that are not the majority language of society. Preschool might be one of the first and few environments where they experience the majority language. The present study investigated how preschool teachers communicate with monolingual English preschoolers and preschoolers learning English as an additional language (EAL). We recorded and transcribed four hours of naturalistic preschool classroom activities and observed whether and how preschool teachers tailored their speech to children of different language proficiency levels and linguistic backgrounds (monolingual English: $n=13$; EAL: $n=10$ ), using a suite of tools for analysing quantity and quality of speech. We found that teachers used more diverse vocabulary and more complex syntax with the monolingual children and children who were more proficient in English, showing sensitivity to individual children's language capabilities and adapting their language use accordingly.
\end{abstract}

Keywords: child-directed speech; English as an additional language; language acquisition; naturalistic observation

\section{Introduction}

In recent decades, society has become increasingly linguistically diverse, supported by greater mobility of populations (e.g., in the UK, Office for National Statistics, 2017; across the EU, Eurostat, 2018; and in the USA, Department of Homeland Security, 2018). Vertovec (2007) coined this phenomenon of people from multiple geographic origins in the UK "super-diversity" (see also Acosta-Garcia \& Martinez-Ortiz, 2013;

(C) The Author(s), 2022. Published by Cambridge University Press. This is an Open Access article, distributed under the terms of the Creative Commons Attribution licence (http://creativecommons.org/licenses/by/4.0), which permits unrestricted re-use, distribution and reproduction, provided the original article is properly cited. 
Spoonley, 2013; Wiley, 2017). As a consequence of this super-diversity, language diversity increases. As a result, young children in our society become more likely to speak a variety of different first languages that are not the majority language of society. For instance, in January 2019, 21.2\% of pupils in state-funded primary schools in England did not speak English as their first language (Department for Education, 2019).

In the case of the UK, this diversity means that many preschool children do not speak English at home and often only use or are exposed to English as an additional language $(\mathrm{EAL})^{1}$. As the current policy of the UK Government is to provide free childcare for all children from 3 years, and for children from lower economic backgrounds from 2 years, young children often tend to spend at least 15 hours a week at preschool. For EAL children, preschool might be one of the few environments where they experience English, the majority language of society. Many of these EAL children will initially not be as proficient in English as their monolingual English peers, and some may possess none or only minimal English. A pressing issue encountered by preschool teachers in the UK is how to communicate with these children and help them acquire the English language (Hutchinson, 2018), especially when the children first attend preschool. This is not only important for integrating EAL children into the preschool, and later school, environment; it also has implications for the children's ultimate academic achievement, as students who are less proficient in English when beginning reception year in school tend to be less successful throughout their schooling (e.g., Guerrero, 2004; Reardon, 2013; Snow, Burns \& Griffin, 1998; von Hippel, Workman \& Downey, 2017). Potential first steps to addressing this issue would be to find out, in a natural preschool environment, how preschool teachers speak to EAL children, and then determine which linguistic features of preschool teacher talk relate to EAL children's language development. The present study focused on examining how preschool teachers speak to EAL children.

\section{Linguistic input and monolingual language development}

There is ample literature that has looked into the relation between caregiver language input and English language learning in monolingual children (see Hoff, 2006 for a review). A landmark study by Hart and Risley (1995) described parents' language use with monolingual English children in their home and its relation with the children's vocabulary. They followed 42 American families for 2.5 years, observing the quantity of caregiver language use. Of note, they found that children from a high socioeconomic status (SES) family were, on average, exposed to 153,000 more words per week compared to those from a low SES family, leading to a 30 million word gap between the linguistic experience of a child from high compared to low SES by age 3 . The children who were exposed to more language, in terms of number of word tokens, word types, and sentences, had a larger vocabulary. In another similar study, Huttenlocher, Haight, Bryk, Seltzer, and Lyons (1991) found that higher frequency words in caregiver speech were acquired earlier by the child. Taken together, these findings suggest that early language input, in particular the quantity of input, plays an important role in vocabulary development (Cartmill et al., 2013; Chang \& Monaghan, 2019; Rowe, 2012).

\footnotetext{
${ }^{1}$ EAAL' is a term typically used in the UK education context. The term does not refer to proficiency but simply exposure (however minimal) to an additional language (i.e., English) which is not a learner's first language. Therefore, the term 'EAL children' encompasses a heterogeneous group of children who speak different first languages and vary in terms of English language proficiency.
} 
Besides quantity, quality of caregiver speech is also related to monolingual children's language skills (see Rowe \& Zuckerman, 2016, for a review). For instance, Newman, Rowe, and Ratner (2016) found that repetitiveness in maternal speech at 7 months, as measured by type-token ratio (TTR), was a significant predictor of monolingual children's language score at 24 months. Another study by Rowe (2012) studying slightly older children found that greater numbers of word types and rare words (i.e., infrequent words) in caregiver language input at 30 months were associated with higher scores on a vocabulary measure at 42 months. These results were similar to those in a study by Huttenlocher, Waterfall, Vasilyeva, Vevea, and Hedges (2010) that found that number of word types in caregiver speech is a significant predictor of number of word types in later child speech. These findings indicate that quality, in terms of lexical diversity, as well as quantity of the language input is crucial to early language acquisition.

Apart from lexical diversity, other measures of quality also influence monolingual children's language development. Huttenlocher et al. (2010) analysed occurrences of different parts of speech and syntactic patterns (e.g., noun phrases and verb phrases) and ways of combining clauses (e.g., coordination, adjunct clauses, and relative clauses) in caregiver and child speech. These features in caregiver speech were predictive of their presence in later child speech, demonstrating how syntactic complexity in language input affects children's syntactic development. Further, more recent studies have found that the use of $w h$ - questions by fathers at 24 months was related to children's vocabulary skills at 36 months (Rowe, Leech \& Cabrera, 2016), and parents' use of decontextualised talk, language that is removed from the here and now (Snow, 1990), at 42 months was predictive of children's vocabulary skills at 54 months (Rowe, 2012). In summary, the quality of early language input at both the vocabulary level and in terms of syntactic variation is critical to children's language development.

Further to linguistic input from parents, research on monolingual children's early language development has also explored linguistic input from preschool teachers. Some studies (e.g., Dickinson \& Smith, 1994; Huttenlocher, Vasilyeva, Cymerman \& Levine, 2002; McCartney, 1984) have examined the relation between the linguistic input that monolingual children receive from preschool teachers and their language growth in the short-term. These studies have yielded similar conclusions to those investigating the home language environment, in that the quality of preschool teacher talk is correlated with monolingual preschoolers' language development. For example, Huttenlocher et al. (2002) observed and analysed audio recordings of the speech of teachers in 40 different preschool classrooms and found that the syntactic complexity of the linguistic input that a child received from the teachers, as measured by the proportion of multi-clause sentences in teacher speech, was positively correlated with their gain of scores on a syntax comprehension test over a year. This implies that the syntactic structure of preschool teachers' speech can influence children's development of syntax.

Preschool teacher talk has also been found to have long-term effects on monolingual children's language development. A study that followed a cohort of over 13,000 children in childcare across the USA found that monolingual preschoolers' language development was positively and significantly correlated with the amount of linguistic input from preschool teachers, as measured by the teachers' self-assessment of language quantity (National Institute of Child Health and Human Development Early Child Care Research Network, 2000). Relatedly, Dickinson and Porche (2011) observed children (around 4 years old) and their teachers in preschool during short periods of free play and group time, and later assessed the children's reading comprehension, receptive vocabulary, and word recognition when they were in their fourth grade (mean age $=9 ; 7$ years). They 
found that the preschool teachers' use of low-frequency words (i.e., words beyond the 3,000 most commonly known words by fourth graders) during free play and attentiongetting/holding utterances significantly and positively predicted the children's reading comprehension at fourth grade. In addition, the preschool teachers' use of low-frequency words during free play was a significant predictor of the children's word recognition at fourth grade. Further, the preschool teachers' attempts to correct the preschoolers' utterances during group time and use of analytic talk (defined as utterances that explore cause-and-effect relations or discuss word meanings) during book reading were associated with the children's receptive vocabulary at fourth grade. Mirroring the observations from home language use studies, these results suggest that the quantity and quality of preschool teacher talk is highly influential on children's later language abilities.

\section{Linguistic input and EAL language development}

In contrast to the numerous studies looking into monolingual young children's linguistic input at home and at preschool, there is comparatively little research focusing on the linguistic input children learning an additional language receive. It has been shown that for bilingual and EAL children, development of vocabulary, morphology, and grammar is related to the quantity of input across a combination of home environment and preschool settings (see Paradis, 2011, and Unsworth, 2016a, for a review). Studies have also investigated the quality of input to children with EAL, where quality has tended to be limited to investigations of the variety of input from the child's two languages or range of early literacy-related activities (Unsworth, 2016b; Unsworth, Brouwer, de Bree \& Verhagen, 2019).

Bowers and Vasilyeva (2011) directly compared monolingual English and EAL preschoolers' language development in relation to some linguistic features of preschool teacher talk. They observed and audio-recorded the speech of preschool teachers across 10 classrooms, each for about 1.5 hours. They also administered a vocabulary test to the children at two points in time, a year apart, to measure the children's English receptive vocabulary. Analyses of the transcripts of the audio recordings focused on how input quantity (number of word tokens), lexical diversity (number of word types), and syntactic complexity (in terms of mean length of utterances; MLU) of the preschool teachers influenced the children's vocabulary scores. Although the monolingual English children performed better on the vocabulary test than the EAL children at the start of the study, findings revealed no difference in the average growth of vocabulary scores between the two language groups. However, different factors contributed to the gain of vocabulary scores of the two language groups. Lexical diversity of teacher talk significantly and positively predicted the monolingual English children's vocabulary scores, whereas the growth of vocabulary scores of the EAL group was predicted by increasing quantity and decreasing syntactic complexity of the teacher talk.

Based on their results, Bowers and Vasilyeva (2011) suggested that the monolingual English and EAL groups were at different stages of language learning, and distinct linguistic features in the input they received may be more influential on their lexical development at these different stages. The EAL children may still be in early stages of lexical development, and thus need more exposure to high-frequency words than their monolingual peers in order to learn those words. Also, shorter utterances may have helped the EAL children to segment and comprehend the utterances more easily. The monolingual English children, however, may have been more ready for exposure to words 
that are lower in frequency in order to learn these new words. Although this study yielded some interesting findings regarding the relations between specific linguistic features of preschool teachers' speech and preschoolers' language development, it did not differentiate between the linguistic input to the monolingual English and EAL children - a direct comparison of the linguistic input to the two language groups with a more detailed examination of the lexical and syntactic features of this language use could provide us with a clearer picture of how linguistic input at preschool (differentially) influences monolingual English and EAL children's language development.

According to speech accommodation theory (Street \& Giles, 1982), individuals tend to adjust their language to enhance comprehensibility for the listener, by matching pronunciation, vocabulary use, and grammatical structures between speakers (Pickering \& Garrod, 2013). Such accommodation across linguistic structures is well-attested in native speakers communicating with non-native speakers (Giles, Coupland \& Coupland, 1991; Long, 1983). One of the first studies to comprehensively investigate accommodation in grammar and lexis in child-directed speech found that adults adjusted their MLU and variety of vocabulary according to the age of children from newborn to 12 years old, but not the set of words from which their vocabulary was drawn (Hayes \& Ahrens, 1988). More recently, Barnes, Oliveira, and Dickinson (2019) showed that preschool teachers are capable of using a range of language accommodation strategies - simplification of vocabulary and reduction in complexity of syntax - when teaching children who are linguistically at risk. Therefore, it is likely that preschool teachers speak differently to monolingual and EAL children based on their differing language proficiency levels.

\section{Measurements of quantity and quality of language use}

Previous studies have used various indices to measure quality markers of children's language environment that relate to language development in terms of lexical diversity and syntactic complexity (Rowe, 2012). For lexical diversity, two commonly used measures are number of word types (e.g., Bowers \& Vasilyeva, 2011; Rowe, 2012) and typetoken ratio (e.g., Youmans, 1990). However, both of these measures are influenced by the size of the corpus in that the type-token ratio reduces as the number of tokens increases (Richards, 1987). A solution to this is to use a mathematically transformed index of the type-token ratio. The Guiraud Index (GI), the number of word types divided by the square root of the number of word tokens, has been found to offer an effective transformation that reflects lexical diversity between different-sized corpora (van Hout \& Vermeer, 2007). Therefore, GI is a better measure of lexical diversity than number of word types and type-token ratio, because number of types and tokens are generally highly correlated. For syntactic complexity, again, a range of indices have been used in previous studies. Apart from MLU (e.g., Bowers \& Vasilyeva, 2011) and incidences of different parts of speech (e.g., Huttenlocher et al., 2010), which are readily available on the Child Language Analysis (CLAN; MacWhinney, 2000) program, studies of child L1 exposure (e.g., Cameron-Faulkner, Lieven \& Tomasello, 2003) have used incidences of different utterance construction types (e.g., wh- questions, copulas, and clause combinations, such as relative clause use) to measure syntactic complexity in caregiver speech. CameronFaulkner and Noble (2013) found greater use of these indicators of syntactic complexity in children's books than caregiver speech, which they suggested could be a factor behind the benefit of shared reading for language development. Relatedly, Rowe (2012) found that syntactic complexity was associated with decontextualised talk, which in turn was found to be beneficial for children's language development. 
Studies of L2 language learning have frequently employed similar sets of measures, but they have also applied additional measures that reflect a greater degree of sophistication to determine the syntactic structures that are present in, and produced by, L2 learners (e.g., Alexopoulou, Michel, Murakami \& Meurers, 2017; Bulté \& Housen, 2018, 2019). For example, Crossley and McNamara (2014) investigated L2 learners grammatical constructions in essays in early and later stages of L2 language learning. They employed CohMetrix (McNamara, Graesser, McCarthy \& Cai, 2014), a tool that measures the use of various lexical categories, range of vocabulary, syntactic structures, as well as the semantic cohesion of text. Coh-Metrix utilises a version of the Charniak (2000) syntactic parser, with precision and recall exceeding 90\%. Crossley and McNamara (2014) studied a variety of Coh-Metrix measures for their ability to discriminate earlier and later L2 language learning sophistication in terms of syntactic structure variety and syntactic complexity. They found that left embeddedness (i.e., number of words before main verb), number of modifiers per noun phrase, syntactic similarity (an index based on the proportion of intersecting syntactic nodes between sentences, reflecting whether learners use a narrow or wide range of syntactic structures), incidence of verb phrases, and incidence of negation distinguished beginning from more advanced L2 learners. The availability of tools such as Coh-Metrix for analysing variety of uses of vocabulary and syntactic structures provides an exciting opportunity for researchers in child language development to apply a broader range of text analysis tools to analyse children's language environment than have typically been employed in the past (Meurers, 2012; Meurers \& Dickinson, 2017; Monaghan \& Rowland, 2017). In the present study, we used these tools to provide a comprehensive analysis of vocabulary and syntactic structure usage in the preschool language environment.

\section{Aims of the present study}

The aim of the present study was to apply this broader set of analytical tools to provide a detailed description of the linguistic environment of a preschool classroom containing both monolingual English and EAL children, combining methods from second language acquisition with those deployed in first language acquisition. Based on previous studies of preschool teachers' speech (Bowers \& Vasilyeva, 2011; Dickinson \& Porche, 2011) and speakers' tendency to adjust to interlocutors in speech exchange (Pickering \& Garrod, 2013), we anticipated that preschool teachers would accommodate their language to the children's linguistic background, but it was not clear for which linguistic features this adaptation might occur. Through building and analysing a corpus of preschool teacher talk, the present study observed whether and how preschool teachers tailored their interaction, in terms of quantity and quality, to children of different linguistic backgrounds (monolingual English vs. EAL), who varied in their levels of English language proficiency.

The measures of quantity of linguistic input that we applied pertain to the amount of exposure available in the input, which included number of word types, number of word tokens, and number of utterances. Our measures of the quality of linguistic input relate to diversity and complexity of the input, and we selected lexical diversity (GI) and several measures of syntactic complexity (MLU, incidences of different parts of speech, left embeddedness, number of modifiers per noun phrase, syntactic similarity, incidence of verb phrases, and incidence of negation). We describe these measures in more detail in the Method section. Observation of a preschool classroom was done through video and audio 
recording. The recordings were then transcribed, and utterances were distinguished in terms of towards which child or children the preschool teachers' speech was directed.

Based on observations of adjustments of vocabulary and syntactic complexity according to children's age (Hayes \& Ahrens, 1988) and sensitivity to children who are linguistically at-risk (Barnes et al., 2019), we predicted that preschool teachers would use language greater in quantity, lexically more diverse, and syntactically more complex with the children who were more proficient in English and/or those who belonged to the monolingual English group. Alternatively, if the preschool teachers were not adapting their language to the children's language proficiency and linguistic backgrounds, then their language to all the children would be similar in quantity, lexical diversity, and syntactic complexity. We conducted two sets of analyses to test these predictions. The first investigated distinctions in the characteristics of speech directed at monolingual English versus EAL children. The second investigated how speech was tailored to the individual language skills of the children, both monolingual and with EAL.

\section{Method}

\section{Participants}

In collaboration with a preschool in the North-West of England, a class of 3- to 4-yearolds, with a mix of monolingual English and EAL children, and the teachers who worked in that classroom were recruited for the study. Twenty-three children $\left(M_{\text {age }}=4 ; 0\right.$ years, range $=3 ; 8-4 ; 4$ years), 13 monolingual English and 10 EAL, took part in the study. The EAL group consisted of children speaking the following languages: Czech $(n=1)$, Dutch $(n=1)$, French $(n=1)$, German $(n=3)$, Greek $(n=1)$, Japanese $(n=2)$, Malay $(n=1)$, Russian $(n=1)$, Spanish $(n=2)$, and Thai $(n=1)$. At least one of the parents of all children, except for one monolingual child where both parents self-reported to have completed secondary school, self-reported to hold degree- or higher-level qualifications. See Table 1 for other demographic information of the children. Seven female teachers took part in the study. All, but one, of them were monolingual English speakers. The remaining teacher was a native Chinese speaker who was also proficient in English (selfreported number of years speaking English $=28$ ). Of the seven teachers, five were Early Years Foundation Stage (EYFS) qualified (Department for Education, 2017) - with four

Table 1. Demographic information of children

\begin{tabular}{lcc}
\hline & Monolingual English & EAL \\
\hline Number & 13 & 10 \\
\hline Male & 9 & 7 \\
\hline Female & 4 & 3 \\
\hline Mean age $^{1}$ & $4 ; 01.02$ & $3 ; 11.24$ \\
\hline Range of age $^{1}$ & $3 ; 08.10-4 ; 04.06$ & $3 ; 09.07-4 ; 03.11$ \\
\hline Average number of years exposed to English $^{1,2}$ & $4.08(0.18)$ & $2.23(1.61)$ \\
\hline Proportion $^{2}$ exposure to English at home ${ }^{2}$ & $100 \%(0.00 \%)$ & $18.13 \%(22.42 \%)$ \\
\hline
\end{tabular}

Notes. ${ }^{1}$ Calculated at the first recording session.

${ }^{2}$ Standard deviations are presented in parentheses. 
being key staff of the classroom (i.e., acting as key person for some children in the classroom) - and two were supply teachers.

\section{Language proficiency}

Three subtests (Sentence Structure, Word Structure, and Expressive Vocabulary) of the Clinical Evaluation of Language Fundamentals - Preschool-2 (CELF-P2; Wiig, Secord \& Semel, 2004) were selected to enable a measure of children's Core Language ability. The test was administered to every child close to the first recording session (spanning from one week before to one week after the recording session). The Sentence Structure subset contained 22 items which required children to point to one of four pictures that matched the verbal description provided by the experimenter. The Word Structure subset consisted of 24 items for which children had to complete the experimenter's verbal description of a picture. The Expressive Vocabulary subset contained 20 items that required children to answer the experimenter's question regarding a picture. The scores of all three subsets were standardised by chronological age, and the standardised scores were summed to obtain a Core Language score. The Core Language score provided information about each child's English language proficiency, and enabled us to determine the English language level of the monolingual and EAL children (against norms for monolingual children) for their age. One monolingual English and one EAL child did not complete the CELF-P2 as they joined the study after recording had started. In addition, one child in the monolingual English group was registered with special educational needs. These three children were excluded from the analysis of language proficiency.

An independent t-test revealed that, as expected, the monolingual English children had significantly higher English Core Language standard scores than the EAL children, $t(11.96)=4.25, p=.001, g=2.02\left(M_{\text {Monolingual }}=106.82, S D_{\text {Monolingual }}=11.48 ; M_{E A L}=\right.$ $\left.74.11, S D_{E A L}=20.61\right)$. We used Hedge's $g$ as a measure of effect size which is appropriate for relatively small, and varying, sample sizes.

\section{Apparatus}

Four video cameras were used to video-record the whole classroom during each recording session. Every teacher who worked in the classroom was required to carry around a small portable audio recorder during the recording sessions in order to clearly record their speech. The number of audio recorders used per session varied between two and three, depending on the number of teachers present.

\section{Procedure}

Parents and preschool teachers were notified of the study approximately 1 month before the study commenced, and informal information sessions were held at pick-up time for them to ask questions about the study during that month. Parental consent for the children and consent from the teachers was gained 2 weeks prior to the first recording session. Three children whose parents did not give consent for the study attended another classroom during the recording sessions. The whole classroom was video- and audio-recorded 1 hour per week for 4.5 months, the present data focused on the first 4 weeks of the recording period (only four teachers, including the bilingual teacher and one non-EYFS-qualified teacher, were present during the first 4 weeks). The children and teachers engaged in their usual 
routines and activities during the recording sessions. The recorded sessions contained a range of activities, including story time, snack time, object play, planned teaching activities, painting, and individual and group conversations. These activities were representative of the range of daily activities of a typical preschool classroom.

\section{Transcription}

All video and audio recordings were orthographically transcribed using the Codes for Human Analysis of Transcripts transcription (CHAT) system using CLAN (MacWhinney, 2000). Children and teachers were assigned unique participant codes to ensure anonymity. Only conversations between the teachers and children were transcribed (i.e., interactions amongst children were not included), and utterances were coded for intended recipient(s) (i.e., a specific child or various children). Intended recipient(s) were identified by the mention of names in an utterance, on-going conversations, and in cases where it was unclear, physical proximity to the speaker. When an utterance was directed at multiple recipients (e.g., during group activity), all recipients were coded.

Although the classroom could be very noisy, our use of audio recorders in addition to the camcorders allowed us to hear most of the conversations between the teachers and children clearly. In cases where it was too difficult or impossible to work out what was spoken, the code 'xxx' was used. Only 6.63\% (204 out of 3,079 utterances) of the teacher utterances contained inaudible segments. These utterances were excluded in our analyses of syntactic complexity; whereas any audible parts of these utterances were still included in the lexical diversity analyses. Coh-Metrix provides a parse for incomplete utterances, and in the case of ambiguity it applies the statistically most likely parse to the utterance.

\section{Reliability}

The recordings were transcribed by three transcribers. One of the three transcribed a 5 -minute segment transcribed by each of the other two transcribers. An utterance boundary analysis was used to determine the reliability of transcription between transcribers. Utterances were grouped into conversational turns (average agreement between the two transcriber pairs was $85.1 \% ; 81.0 \%$ and $89.2 \%$ respectively) and the agreement of utterance boundaries within each turn was determined. When there was a disagreement on conversational turn, that portion of the transcript was divided into conversational turns using the higher number for utterance boundary analysis. The average agreement on utterance boundaries between the two transcriber pairs was $85.7 \%(80.3 \%$ and $91.1 \%$ respectively), which is high compared to typical inter-rater agreement on utterance boundaries in speech (e.g., 52.7 - 62.4\%; Stockman, 2010).

Further, Cohen's Kappa was used to determine inter-rater reliability on the coding of addressees. For each utterance, whether each addressee was tagged by a transcriber was coded. A Cohen's Kappa was then calculated for each addressee. Across all transcribers coding each of the addressees, the average Cohen's Kappa was .89 $(S D=.17$, range $=.49$ $1.00)$, indicating overall high reliability.

\section{Preschool teacher talk features}

To characterise the preschool teachers' language input, we coded the transcripts for quantity and quality measures of the language environment. 


\section{Quantity variables}

Number of word types, number of word tokens, and number of utterances were used as indices of the amount of language used by the preschool teachers. All quantity variables were calculated through CLAN. These language features were measured for each of the four recording sessions separately, and the average used for analysis.

\section{Quality variables}

The quality of preschool teacher talk in the present study was measured by indices of lexical diversity and syntactic complexity. Lexical diversity was measured through GI and density scores (relative frequencies per 1,000 word tokens) of the following parts of speech: adjectives, adverbs, conjunctions, coordinators, determiners, nouns, numerals, prepositions, pronouns, and verbs. For syntactic complexity, we selected a set of measures that have reflected syntactic structural differences in SLA research, and that extend the range of previously used measures of syntactic complexity in studies of first language research. The following measures were used: MLU, left embeddedness (SYNLE, the number of words appearing in the utterance before the first verb), mean number of modifiers per noun phrase (SYNNP), syntactic structure similarity (SYNSTRUTt, a measure of the variation in the syntactic structures employed across utterances ${ }^{2}$ ), and density scores of different syntactic patterns, including noun phrase (DRNP; i.e., the proportion of phrases that were noun phrases in the utterances), verb phrase (DRVP), and negation expressions (DRNEG).

To measure some of the key construction types as features of child-directed speech by caregivers identified by Cameron-Faulkner and colleagues (Cameron-Faulkner et al., 2003; Cameron-Faulkner \& Noble, 2013), we assessed the density score of copulas (i.e., proportion of word tokens that were copulas across the utterances), the combined density score of interrogative determiners and interrogative pronouns to reflect question use, and the density scores of relative pronouns, conjunctions, and coordinators as indices of clause combination to reflect complex constructions (see also Huttenlocher et al., 2010). We also measured the density score combining demonstrative determiners and demonstrative pronouns as a proxy for decontextualised talk, with a higher value denoting language that is less decontextualised. Demonstratives can be used as reference to events and objects that are present in the here and now, which would be the opposite of decontextualised talk (Snow, 1990), though Rowe's (2012) characterisation of decontextualised talk focuses on explanations, narrations, and talk about pretend events. The density scores of these identified syntactic subcategories were treated as measures of syntactic complexity.

Given that these quality measures of teacher talk are more informative for a larger and richer text sample, measures were taken for all four recording sessions combined.

MLU was obtained through CLAN; GI was computed from the numbers of word types and tokens obtained through CLAN; density scores of different parts of speech were computed using the frequencies of each part of speech and the number of word tokens obtained through CLAN; whereas all other syntactic complexity indices were obtained through Coh-Metrix (McNamara et al., 2014).

\footnotetext{
${ }^{2}$ SYNSTRUTt is defined as "the proportion of intersection tree nodes between all sentences within a text" and operationalises the similarity in syntactic structures used within a text.
} 


\section{Results}

We first describe the overall language use by the preschool teachers in the classroom. Then, we present analyses of the language directed towards the two language groups, before investigating variation in the language directed towards individual children.

\section{General linguistic environment of a preschool classroom}

In the observed preschool classroom, there were, on average, 773 utterances, 4,667 word tokens, and 563 word types per hour of observation, with a GI of 8.24. Compared to the findings of Hart and Risley's (1995) study on the home linguistic environment of younger children $(0-3$ years), the preschool classroom in the present study provided a high quantity of language to children, and though the context was different, the level of exposure was found to exceed that of the home environment of children from professional (high-SES) families (see Table 2).

\section{Comparing linguistic input to monolingual English and EAL children}

We next investigated the speech that had been coded as directed towards each individual child. The quantity measures reflect the amount of language per hour of the recording sessions, whereas the quality indices were measured across all four recording sessions. To determine whether the preschool teachers communicated differently to the EAL children when compared to their monolingual English peers, linear-mixed effect (LME) models (Baayen, Davidson \& Bates, 2008), with language group as a fixed effect (using the monolingual English group as the reference level) and individual children and teachers as random intercepts, were fitted to all linguistic features of preschool teacher talk using the lme4 package (Bates, Mächler, Bolker \& Walker, 2015) in R (R Core Team, 2021). LME modelling allows us to examine the systematic differences between language group while taking into account individual differences of children and teachers (Jiang, 2007). Numbers of word tokens and density scores of numerals and DRNEG were square-root transformed to improve fit to a normal distribution for analysis. The means and standard deviations of the indices of all linguistic features in the teachers' speech and the fixed effect of language group in the LME models are presented in Table 3 (see Appendix A for further details). The $\mathrm{p}$-values were not transformed for multiple comparisons so as not to overlook any effects that may be useful for distinguishing small groups of children.

Table 2. Comparison of general linguistic environment with Hart and Risley (1995)

\begin{tabular}{lcccc} 
& & \multicolumn{3}{c}{ Hart \& Risley (1995) } \\
\cline { 3 - 5 } & $\begin{array}{c}\text { Present } \\
\text { study }\end{array}$ & $\begin{array}{c}\text { Professional } \\
\text { families }\end{array}$ & $\begin{array}{c}\text { Working-class } \\
\text { families }\end{array}$ & $\begin{array}{c}\text { Families on } \\
\text { welfare }\end{array}$ \\
\hline Number of utterances & 773 & 487 & 301 & 176 \\
\hline Number of word tokens & 4667 & 2153 & 1251 & 616 \\
\hline Number of word types & 563 & 382 & 251 & 167 \\
\hline GI & 8.24 & 8.23 & 7.10 & 6.73 \\
\hline
\end{tabular}

Notes. All measures were means per hour. The numbers for the present study were summed for all teachers present during the recording sessions. 
Table 3. Means, standard deviations, fixed effect of language group in the LMEs, and estimated effect sizes of all identified linguistic features of preschool teacher talk in the utterances directed at the Monolingual English and EAL groups

\begin{tabular}{|c|c|c|c|}
\hline Linguistic feature & $\begin{array}{l}\text { Monolingual } \\
\text { English } \\
M(S D)\end{array}$ & $\begin{array}{c}\text { EAL } \\
M(S D)\end{array}$ & $\begin{array}{c}\text { Fixed effect of language } \\
\text { group in LMEs } \\
\text { (monolingual English vs. EAL) }\end{array}$ \\
\hline \multicolumn{4}{|l|}{ Quantity } \\
\hline Number of word types & $143.65(83.87)$ & $87.33(35.78)$ & $t=-2.029, p=.055, \eta_{\mathrm{p}}{ }^{2}=0.16$ \\
\hline Number of word tokens & $462.90(341.43)$ & $260.05(167.21)$ & $t=-1.930, p=.058, \eta_{\mathrm{p}}^{2}=0.05$ \\
\hline Number of utterances & $60.31(39.66)$ & $51.99(41.03)$ & $t=-0.405, p=.687, \eta_{\mathrm{p}}^{2}=0.00$ \\
\hline \multicolumn{4}{|l|}{ Quality } \\
\hline \multicolumn{4}{|l|}{ Lexical diversity } \\
\hline GI & $8.84(2.28)$ & $7.28(0.83)$ & $t=-2.372, p=.027, \eta_{\mathrm{p}}{ }^{2}=0.21$ \\
\hline \multicolumn{4}{|c|}{ Parts of speech (density scores) } \\
\hline Adjectives & $27.73(15.10)$ & $23.55(10.43)$ & $t=-0.836, p=.413, \eta_{\mathrm{p}}{ }^{2}=0.03$ \\
\hline Adverbs & $85.92(16.22)$ & $92.35(14.88)$ & $t=1.332, p=.187, \eta_{\mathrm{p}}{ }^{2}=0.02$ \\
\hline Conjunctions & $15.87(5.02)$ & $9.83(5.78)$ & $t=-1.227, p=.234, \eta_{p}^{2}=0.07$ \\
\hline Coordinators & $25.88(6.13)$ & $21.02(9.74)$ & $t=-0.132, p=.897, \eta_{\mathrm{p}}{ }^{2}=0.00$ \\
\hline Determiners & $81.42(25.63)$ & $87.04(30.43)$ & $t=0.001, p=.999, \eta_{\mathrm{p}}^{2}=0.00$ \\
\hline Nouns & $179.39(32.00)$ & $181.94(24.20)$ & $t=1.671, p=.109, \eta_{p}^{2}=0.12$ \\
\hline Numerals & $8.99(6.73)$ & $13.16(18.24)$ & $t=1.259, p=.233, \eta_{\mathrm{p}}^{2}=0.07$ \\
\hline Prepositions & $56.13(11.05)$ & $48.55(5.04)$ & $t=-2.134, p=.045, \eta_{\mathrm{p}}{ }^{2}=0.18$ \\
\hline Pronouns & $166.65(30.69)$ & $178.49(24.17)$ & $t=-0.527, p=.600, \eta_{\mathrm{p}}^{2}=0.00$ \\
\hline Verbs & $134.11(26.82)$ & $131.85(23.24)$ & $t=0.223, p=.825, \eta_{\mathrm{p}}^{2}=0.00$ \\
\hline
\end{tabular}

\section{Syntactic complexity}

\begin{tabular}{lllc}
\hline MLU & $6.84(1.11)$ & $5.00(1.13)$ & $t=-3.246, p=.004, \eta_{\mathrm{p}}{ }^{2}=0.36$ \\
\hline SYNLE & $1.46(0.39)$ & $0.96(0.37)$ & $t=-2.098, p=.050, \eta_{\mathrm{p}}{ }^{2}=0.19$ \\
\hline SYNNP & $0.48(0.16)$ & $0.43(0.10)$ & $t=-1.851, p=.078, \eta_{\mathrm{p}}{ }^{2}=0.14$ \\
\hline SYNSTRUTt & $0.11(0.01)$ & $0.12(0.01)$ & $t=2.697, p=.013, \eta_{\mathrm{p}}{ }^{2}=0.26$ \\
\hline
\end{tabular}

Syntactic patterns (density scores)

\begin{tabular}{lccc}
\hline DRNP & $328.27(17.49)$ & $329.05(19.89)$ & $t=0.622, p=.541, \eta_{\mathrm{p}}{ }^{2}=0.02$ \\
\hline DRVP & $256.86(18.46)$ & $245.22(35.83)$ & $t=0.319, p=.751, \eta_{\mathrm{p}}{ }^{2}=0.00$ \\
\hline DRNEG & $20.62(8.93)$ & $19.66(11.99)$ & $t=-0.279, p=.783, \eta_{\mathrm{p}}{ }^{2}=0.00$ \\
\hline
\end{tabular}

Syntactic subcategories (density scores)

\begin{tabular}{lccc}
\hline Copulas & $28.05(7.59)$ & $31.59(10.11)$ & $t=-0.310, p=.758, \eta_{\mathrm{p}}{ }^{2}=0.00$ \\
\hline Demonstratives & $15.12(3.65)$ & $25.33(9.72)$ & $t=1.521, p=.132, \eta_{\mathrm{p}}{ }^{2}=0.03$ \\
\hline Interrogatives & $11.39(5.86)$ & $13.38(4.25)$ & $t=-0.841, p=.403, \eta_{\mathrm{p}}{ }^{2}=0.01$ \\
\hline Relative pronouns & $6.79(2.85)$ & $6.69(4.27)$ & $t=-0.457, p=.649, \eta_{\mathrm{p}}{ }^{2}=0.00$ \\
\hline
\end{tabular}

Notes. Means are based on untransformed data. Uncorrected significant differences between language groups are presented in bold. All density scores were based on density per 1,000 word tokens. 
As effect sizes are independent of sample size, attention to the effect sizes is also informative - if the p-values accompany very small effect sizes then the ability of the measure to distinguish the groups should be interpreted with caution. Effect sizes were estimated using partial eta-squared. However, note that these effect size values are very conservative estimates of the effect of language group on the children's language input, as a lot of the variance of language group would have been captured by the random effect of children, which is nested within language group.

All quantity indices are higher for the monolingual English than the EAL group. For the quality indices, there were also higher values for the monolingual English children, with the exception of SYNSTRUTt, DRNP, some parts of speech measures (adverbs, determiners, nouns, numerals, and pronouns), and most of the indices of syntactic subcategories. For these syntactic subcategories, only relative pronouns yielded higher scores for the monolingual English than the EAL group. The standard deviations of the measures show that there are large differences within the groups, in particular for word tokens and indices of adjectives and numerals.

For the general properties of speech, the language input to the two language groups differed in terms of MLU and GI, with the EAL children receiving shorter utterances and less diverse vocabulary. These were not significant when corrected for by Bonferroni correction for multiple comparisons (i.e., requiring a $\mathrm{p}$-value $<.05 / \mathrm{n}$ where $\mathrm{n}$ is the number of comparisons), but the estimated effect sizes indicate a large effect (Cohen, 1988). Apart from the teachers using marginally significantly more word types and tokens with the monolingual English than EAL children, all other quantity measures did not differ significantly between the two language groups.

Our more exploratory analysis on parts of speech revealed that the teachers used significantly more prepositions with the monolingual English children than with the EAL children, but again this was not significant if corrected for by Bonferroni correction for multiple comparisons, though the estimated effect sizes indicate a medium effect (Cohen, 1988). The teachers' use of other parts of speech with the two language groups was not significant.

For the syntactic complexity indices identified through Crossley and McNamara (2014), SYNLE and SYNSTRUTt in the teachers' speech differed significantly between the two language groups. Note that Bonferroni correction for multiple comparisons would mean that these linguistic features were no longer significantly different between language groups, though the estimated effect sizes indicate a large effect (Cohen, 1988). These results suggest that the EAL children had less exposure to left embedded utterances and were exposed to less diverse syntactic structures. The teachers also used marginally significantly fewer modifiers within noun phrases with the EAL children. All other indices identified through Crossley and McNamara (2014) did not differ significantly between the two language groups.

Analysis on the subcategories of parts of speech identified through Cameron-Faulkner et al. (2003), Cameron-Faulkner and Noble (2013), and Rowe (2012) revealed that the teachers' use of copulas, demonstratives, interrogatives, and relative pronouns were not significantly different between the two language groups.

\section{Relations between preschool teacher talk features and children's language proficiency}

As shown in Figure 1, there was within group variation in English language scores. Our next analysis determined the extent to which preschool teachers adapted their language to 


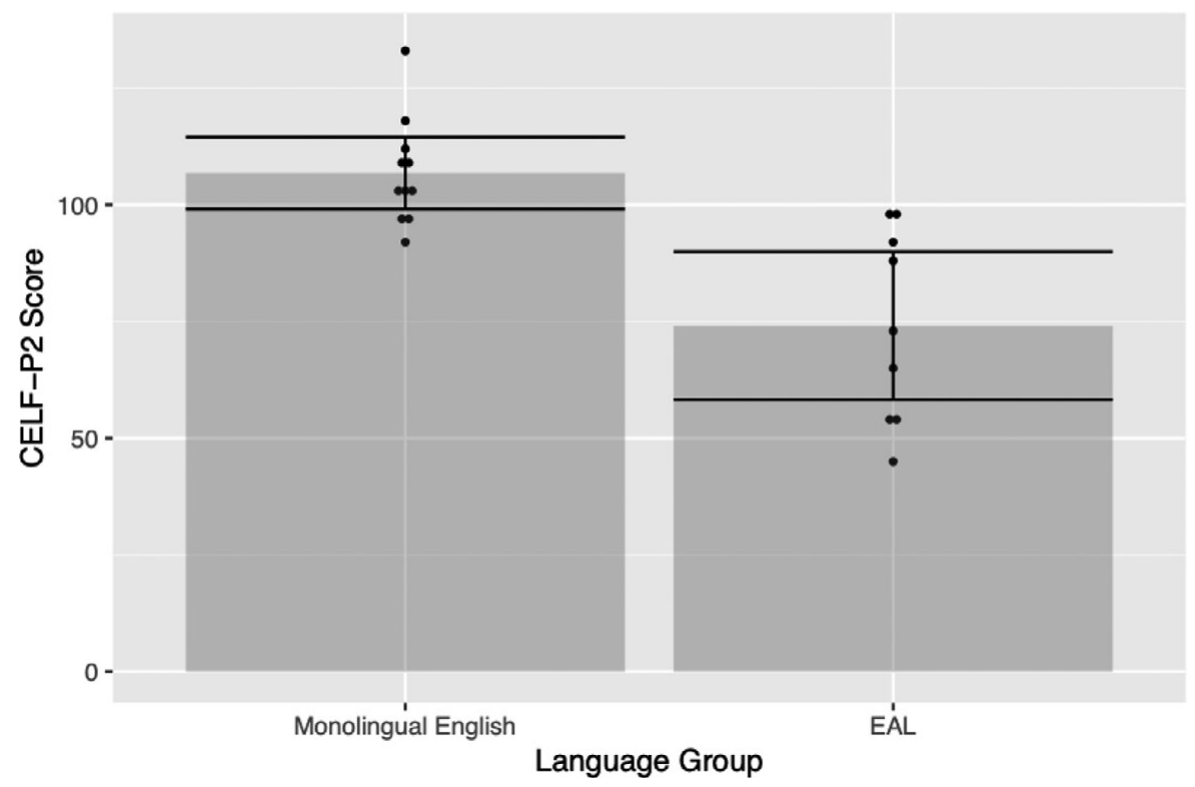

Figure 1. Core Language scores of the monolingual English and EAL children. Each dot represents the score of one child. Error bars represent standard errors.

the individual children's language proficiency, regardless of whether children were monolingual or acquiring EAL. For this analysis, correlations between the children's Core Language scores and all identified teacher talk features were computed. Again, numbers of word tokens and density scores of numerals were square-root transformed to improve fit for analysis. The correlations can be found in Table 4 .

In terms of general linguistic features of teacher talk, none of the quantity measures were significantly correlated with the children's language score.

Positive significant correlations were found between the children's language score and the teachers' MLU and GI, with the MLU correlation still significant after Bonferroni correction for multiple comparisons, meaning that the teachers used longer utterances and more diverse vocabulary with children who were more proficient in English.

With regard to parts of speech, significant correlations between the children's language scores and the density score of conjunctions and pronouns were found, with conjunctions remaining significant after Bonferroni correction for multiple comparisons. These results suggest that the teachers used more conjunctions and fewer pronouns with the children who were more proficient in English.

For syntactic complexity indices identified through Crossley and McNamara's (2014) study of EAL adult language use, positive significant correlations were found between the children's language scores and SYNLE and DRVP, whereas a negative significant correlation was found for SYNSTRUTt. These, except DRVP, were still significant when correcting for multiple comparisons by Bonferroni correction. These results show that the teachers used a greater number of words before the main verb and more verb phrases with the children who were more proficient in English, whereas they used utterances that were more similar in terms of syntactic construction with the children who were less proficient in English. 
Table 4. Means and standard deviations of all identified linguistic features of preschool teacher talk in the whole classroom and their correlation with the children's language proficiency scores

\begin{tabular}{|c|c|c|}
\hline Linguistic feature & Whole classroom & Correlation with CELF-P2 \\
\hline \multicolumn{3}{|l|}{ Quantity } \\
\hline Number of word types & $118.05(71.11)$ & $r=.38, p=.102$ \\
\hline Number of word tokens & $370.70(289.37)$ & $r=.20, p=.396$ \\
\hline Number of utterances & $56.53(39.54)$ & $r=-.14, p=.568$ \\
\hline \multicolumn{3}{|l|}{ Quality } \\
\hline \multicolumn{3}{|l|}{ Lexical diversity } \\
\hline GI & $8.13(1.91)$ & $r=.54, p=.015$ \\
\hline \multicolumn{3}{|l|}{ Parts of speech } \\
\hline Adjectives & $25.83(13.06)$ & $r=.37, p=.111$ \\
\hline Adverbs & $88.84(15.60)$ & $r=-.23, p=.337$ \\
\hline Conjunctions & $13.12(6.08)$ & $r=.65, p=.002$ \\
\hline Coordinators & $23.67(8.16)$ & $r=.10, p=.671$ \\
\hline Determiners & $83.97(27.37)$ & $r=-.32, p=.168$ \\
\hline Nouns & 180.55 (28.09) & $r=.07, p=.758$ \\
\hline Numerals & $10.89(13.07)$ & $r=-.25, p=.281$ \\
\hline Prepositions & $52.69(9.47)$ & $r=.29, p=.208$ \\
\hline Pronouns & $172.04(27.93)$ & $r=-.45, p=.045$ \\
\hline Verbs & $133.09(24.69)$ & $r=.16, p=.501$ \\
\hline \multicolumn{3}{|l|}{ Syntactic complexity } \\
\hline MLU & $6.00(1.44)$ & $r=.78, p<.001$ \\
\hline SYNLE & $1.23(0.45)$ & $r=.74, p<.001$ \\
\hline SYNNP & $0.46(0.13)$ & $r=.12, p=.627$ \\
\hline SYNSTRUTt & $0.11(0.01)$ & $r=-.61, p=.004$ \\
\hline \multicolumn{3}{|l|}{ Syntactic patterns } \\
\hline DRNP & $328.62(18.17)$ & $r=-.16, p=.491$ \\
\hline DRVP & $251.57(27.64)$ & $r=.53, p=.017$ \\
\hline DRNEG & $20.19(10.18)$ & $r=.20, p=.391$ \\
\hline \multicolumn{3}{|l|}{ Identified subcategories } \\
\hline Copulas & $29.66(8.79)$ & $r=-.28, p=.237$ \\
\hline Demonstratives & $19.76(8.64)$ & $r=-.85, p<.001$ \\
\hline Interrogatives & $12.30(5.17)$ & $r=-.37, p=.111$ \\
\hline Relative pronouns & $6.74(3.47)$ & $r=-.42, p=.064$ \\
\hline
\end{tabular}

Notes. Means are based on untransformed data. Standard deviations are presented in parentheses. All $d f \mathrm{~s}=18$ for the correlations. Uncorrected significant correlations are presented in bold. 
Considering the identified subcategories of parts of speech, a positive significant correlation between the children's language scores and the teachers' use of demonstratives was revealed, suggesting that the teachers used more words related to the here and now (i.e., less decontextualised talk) with the children who were less proficient in English. Again, this was still significant after Bonferroni correction for multiple comparisons.

\section{Discussion}

Previous studies of children's early language environment have shown that both quantity and quality of language exposure is critical to children's language development (Rowe \& Zuckerman, 2016). In home environments, children's exposure to language can differ greatly in quantity, creating a gap among children in terms of their early language experience (Hart \& Risley, 1995) which in turn leads to differing vocabulary scores. Children with EAL may arrive at preschool with little prior experience of English, and it is a relatively unknown issue how this gap in their English exposure affects their learning. A key question is how preschool teachers should speak to children whose English language is lower in proficiency than their monolingual English peers - whether they should adapt their language to the child's language level, or to their chronological age. Before this can be answered, finding out how preschool teachers speak to children from EAL backgrounds is an important first step.

The sparse studies of the language environment in preschool of EAL compared to monolingual English children have demonstrated that language development is better supported by vocabulary diversity for the monolingual children, and shorter utterance length and greater quantity was most beneficial to developing vocabulary in the EAL children (Bowers \& Vasilyeva, 2011). However, these previous studies have typically focused on broad, quantity properties of children's language exposure, and studies with adult EAL language learners have identified a wider range of syntactic features that importantly distinguish variation in language proficiency. Furthermore, tools are now readily available for complex, rich analysis of children's language environment to provide insight into detailed characteristics of the linguistic exposure (McNamara et al., 2014). In our study, we exploited this growing availability of corpus analysis tools for a wider and richer analysis of quality of language use.

The primary question we asked was whether and how preschool teachers tailor their language use to children of different linguistic backgrounds (i.e., group differences between monolingual English and EAL children) and levels of language proficiency (i.e., correlations between teacher input characteristics and individual children's language proficiency scores). In order to address this question, we constructed a corpus of preschool teacher talk based on 4 hours of naturalistic observation of a preschool classroom.

We compared the quantity and quality of language input that a group of monolingual English and EAL preschoolers received from their teachers in a natural preschool classroom setting. Importantly, the QUANTITY of language input from the preschool teachers did not differ with respect to the children's language proficiency or linguistic background. Children with lower English language proficiency still received similar amounts of input as the children who were monolingual English. Indeed, the preschool setting in this study offered substantial amounts of linguistic input to the children, even higher than the professional families in Hart and Risley's (1995) study. This substantial quantity of language was present and available for all children in the setting, meaning that 
lower proficiency did not relate to less input from the teachers. Although Hart and Risley examined children in different contexts - home rather than preschool environments - the EAL children in this preschool setting were exposed to more language than the younger monolingual children in Hart and Risley's study, who were at a similar stage to them in language learning. Yet, it has to be noted that when describing the general linguistic environment in the present study, the overall numbers were not based on averages taken from utterances directed at each child. Instead, the numbers were computed based on all preschool teacher utterances within the classroom, so not all utterances and words were addressed to all the children in the classroom. Nonetheless, previous experimental studies have found that children are able to learn words through overhearing speech that is not directed at them (e.g., Akhtar, Jipson \& Callanan, 2001; Gampe, Liebal \& Tomasello, 2012). Further, the present study disregarded peer talk (i.e., talk amongst the children), which has also been found to impact on preschoolers' language development (e.g., Mashburn, Justice, Downer \& Pianta, 2009; Palermo et al., 2014). All considered, the numbers in relation to the general linguistic environment reported in the present study are likely to be reasonable estimates of the amount of the language in the preschool classroom that an average child was exposed to. Our findings, thus, add to the existing literature on language exposure and experiences by extending naturalistic observations to the preschool environment, and are informative for research on the word gap (Hindman, Wasik \& Snell, 2016).

Furthermore, we found that the preschool teachers were adapting their language use either to the children's language proficiency and linguistic backgrounds, or both, such that their language directed at the children who were more proficient in English and those who were monolingual was lexically more diverse and syntactically more complex. In the dynamic setting of the preschool, the staff were still able to modify their language according to the children's language level.

EAL and monolingual English children, early in their preschool careers, have very different distributions of English language proficiency scores. Thus, observations of group differences in language use by preschool teachers are likely to reflect children's language proficiency regardless of whether the children speak a language other than English. Indeed, we found some parallels in the preschool teachers' adaption of language use to children when related to different levels of language proficiency regardless of language background and when related to language background. We found that lexical diversity (GI) and the following measures of syntactic complexity: MLU, SYNLE, and SYNSTRUTt distinguished the EAL and monolingual children and were also correlated with overall language proficiency levels. This suggests that the preschool teachers used less diverse vocabulary, shorter utterances, fewer left embedded utterances, and less diverse syntactic structures with children who were of lower proficiency of English and those who belonged to the EAL group.

A recent systematic review (Langeloo, Mascareño Lara, Deunk, Klitzing \& Strijbos, 2019) of teacher-child interactions with multilingual children noted that teachers tend to use language that is of low complexity with immigrant children learning the majority language of society during free play (e.g., Lara-Alecio, Tong, Irby \& Mathes, 2009) and dialogic book reading (e.g., Ping, 2014). Langeloo et al. raised concerns about the impoverished input to children learning an additional language at school. Yet, this seemingly impoverished input might be adaptive to those children's language development. Children at different stages of development benefit from different features in the language input (Rowe \& Zuckerman, 2016). A child at the age of 7 months benefits from hearing words repeatedly (Newman et al., 2016), whereas a child at the age of 30 months 
benefits from hearing more word types (Rowe, 2012). With the parallels in the present study between the preschool teachers' adaptation of language use to the children's language proficiency and linguistic background, there is evidence that the teachers were sensitive to the children's stages of language development and could adapt the way they speak accordingly, regardless of the children's linguistic background. It is likely that the simplified input to the EAL children was an attempt to provide language ability-appropriate input.

However, this does not mean that the teachers were providing language abilityappropriate scaffolding, as it was impossible to discern causality in the present study. On the one hand, the preschool teachers' language input could be the cause of the effects, such that the language input they provided to the children had an influence on the children's language proficiency. On the other hand, it could be that the effects were driven by the children's language proficiency, such that the quality of the preschool teachers' language was simply a reflection of the children's language use. A longitudinal study looking into how specific linguistic features of preschool teacher talk relate to preschoolers' language development is needed to disentangle the relations between linguistic features of preschool teacher talk and preschoolers' language skills. The study by Bowers and Vasilyeva (2011) provides a first answer to this question, showing greater diversity benefits monolingual children in preschool settings, and short utterances benefit EAL children. This suggests that broader findings showing that lexical diversity and syntactic complexity of children's language input are related to their language proficiency (e.g., Rowe, 2012) may be contingent upon the children's language stage at the point of exposure.

In addition, the preschool teachers' language adaptation to the children's language proficiency and linguistic background involved also their use of verb phrases, conjunctions, demonstratives, and pronouns. The preschool teachers used more verb phrases and conjunctions, but fewer demonstratives and pronouns, when speaking with the children who were more proficient in English. Utterances with a higher density of verb phrases and conjunctions are likely to contain more information with more complex syntax (McNamara et al., 2014); whereas those with a higher density of demonstratives are likely to be about the here and now and less decontextualised, which are easier to process. The significant correlations between the density of verb phrases, demonstratives, and conjunctions and the children's English proficiency provided further evidence that the preschool teachers were adapting their language to individual children's language ability. However, the significant negative correlation between the preschool teachers' use of pronouns and the children's language proficiency was surprising. Pronouns are difficult to learn because they are not subject to certain constraints of word learning, such as mutual exclusivity (e.g, Markman, 1994) and the principle of categorical scope (e.g., Golinkoff, Mervis \& Hirsh-Pasek, 1994). The significant correlation could have been driven by the teachers' use of demonstrative pronouns. It is also possible that the preschool teachers attempted to simplify their utterances by using pronouns in place of long noun phrases to shorten their utterances or to utilise them because of their high frequency to promote speech recognition (Frost, Monaghan \& Christiansen, 2019). Both of these explanations would suggest that the preschool teachers were trying to reduce the syntactic complexity in their language addressed to the children who were less proficient in English and who would find long utterances with complex syntax hard to comprehend. More importantly, the preschool teachers' adaptation of use of verb phrases, conjunctions, demonstratives, and pronouns to the children's language proficiency but not linguistic background provides evidence that the teachers were not simply providing 
simplified input to the EAL children; rather, they were tuning in to each and every child's language ability.

A methodological contribution of the present study is that we have shown how to draw on corpus tools that are established for analysing written text in second language learners to complement research into children's language input. The indices provided by CohMetrix complement the indices readily available in tools (e.g., CLAN) that are traditionally used in children's language environment (Meurers, 2012; Meurers \& Dickinson, 2017; Monaghan \& Rowland, 2017). In particular, analysing phrase- and sentence-level attributes in CLAN often requires additional manual coding, which entails substantial effort and time. Tools that can automatically analyse text at phrase and/or sentence levels (e.g., SYNLE, SYNSTRUTt, DRNP, and DRVP available in Coh-Metrix) can streamline the analysis process. In general, exploiting the different analysers available, such as CohMetrix and Synlex (Lu, 2010), can make it less time-consuming for researchers to gain a more comprehensive view of children's language exposure. However, we note that not all measures of complexity of written language can be directly applied to oral language (e.g., cohesiveness), and they might not fully capture the complexity of oral language (Biber, Gray \& Poonpon, 2011). Researchers should carefully choose the measures that are relevant and sensible for their data.

Unlike some previous studies that only observed children's language environment during one activity, such as book reading (Dickinson \& Porche, 2011) and controlled lab tasks (Newman et al., 2016), the present study included a wide range of activities that would take place in a typical preschool classroom. Tamis-LeMonda, Custode, Kuchirko, Escobar, and Lo (2018) observed parental language input to monolingual English 13month-olds and found that the quantity and quality of maternal language changed as a function of activity. For instance, story time presented ample opportunities for caregivers to verbalise, but feeding did not provide many opportunities for caregivers to speak. Types of words also differed according to activity. For example, there were more shape and number words used during object play and story time compared to mealtime. The present study included observations of a diversity of activities, including story time, snack time, object play, planned teaching activities, painting, and individual and group conversations. The observations in the present study were therefore representative of and presented a good level of information about the general linguistic environment of a typical preschool classroom.

Although the present study has already included a large number of linguistic features of preschool teacher talk compared to other studies (e.g., Bowers \& Vasilyeva, 2011; Huttenlocher et al., 2002), the list was not exhaustive. We have omitted some interesting features in the present study mainly due to practicality. For instance, previous studies have found that maternal responsiveness was a significant predictor of a monolingual child's expressive language (Tamis-LeMonda, Bornstein, Baumwell \& Damast, 1996) and how early a monolingual child achieves basic language milestones (Tamis-LeMonda, Bornstein \& Baumwell, 2001). A possible linguistic feature that we could have included in the present study was the preschool teachers' responsiveness to the children's initiation of conversation. However, as it was impossible to equip children with audio recorders, sound quality did not allow for coding when a child was trying to initiate a conversation and what they were uttering - which in turn made it impossible to code preschool teacher responsiveness.

Another important note about the present study is that the setting involved in the study was a university-based preschool, and the preschool children recruited tended to represent families from higher socio-economic groups. Through informal conversations, 
the preschool teachers recruited for the present study reported not receiving additional formal training on caring for EAL children apart from that in their EYFS training. Yet, the preschool teachers recruited for the present study had substantial experience in caring for EAL children given the large proportion of EAL families in the university population. It would be interesting to see whether the results of the present study would replicate in a setting with teachers that are less experienced in caring for EAL children and children that are from lower SES families.

To conclude, a preschool classroom presents ample opportunities for preschoolers to experience language. Preschool teachers are sensitive to preschoolers' language ability and linguistic background and adapt the quality, but not quantity, of their language use accordingly. Lexical diversity and utterance length of preschool teacher talk and preschool teachers' use of left-embedded sentences and diverse syntactic structures were found to be positively and significantly correlated with the children's language proficiency and related to their linguistic background. In addition, preschool teachers' use of conjunctions, demonstratives, pronouns, and verb phrases were correlated with the children's language proficiency. These findings are in line with the language abilityappropriate scaffolding framework (e.g., Rowe, 2012; Rowe \& Zuckerman, 2016). Yet, the question remains whether the preschool teachers' language input is truly scaffolding and therefore supporting the children's language development, or whether they are merely tuning their language to the children's language proficiency. Future longitudinal studies can explore whether and how these features of preschool teacher talk influence children's language skills and development, and whether these differ for monolingual children and children learning the majority language in addition to their home language.

Acknowledgements. This work was supported by a Leverhulme Trust Doctoral Scholarship (DS-2014-14) and the International Centre for Language and Communicative Development (LuCiD) at Lancaster University, funded by the Economic and Social Research Council (United Kingdom; ES/L008955/1).

\section{References}

Acosta-Garcia, R., \& Martinez-Ortiz, E. (2013). Mexico through a superdiversity lens: Already-existing diversity meets new immigration. Ethnic and Racial Studies, 38(4), 636-649. https:// doi.org/10.1080/01419870.2015.980289

Akhtar, N., Jipson, J., \& Callanan, M. A. (2001). Learning words through overhearing. Child Development, 72(2), 416-430. https://doi.org/10.1111/1467-8624.00287

Alexopoulou, T., Michel, M., Murakami, A., \& Meurers, D. (2017). Task effects on linguistic complexity and accuracy: A large-scale learner corpus analysis employing natural language processing techniques. Language Learning, 67(S1), 180-208. https://doi.org/10.1111/lang.12232

Baayen, R. H., Davidson, D. J., \& Bates, D. M. (2008). Mixed-effects modeling with crossed random effects for subjects and items. Journal of Memory and Language, 59(4), 390-412. https://doi.org/10.1016/ j.jml.2007.12.005

Barnes, E. M., Oliveira, A. W., \& Dickinson, D. K. (2019). Teacher accommodation of academic language during Head Start Pre-Kindergarten read-alouds. Journal of Education for Students Placed at Risk, 24(4), 369-393. https://doi.org/10.1080/10824669.2019.1657868

Bates, D., Mächler, M., Bolker, B., \& Walker, S. (2015). Fitting Linear Mixed-Effects Models Using lme4. Journal of Statistical Software, 67(1), 1-48. doi: 10.18637/jss.v067.i01

Biber, D., Gray, B., \& Poonpon, K. (2011). Should we use characteristics of conversation to measure grammatical complexity in L2 writing development?. Tesol Quarterly, 45(1), 5-35. https:// doi.org/10.5054/tq.2011.244483

Bowers, E. P., \& Vasilyeva, M. (2011). The relation between teacher input and lexical growth of preschoolers. Applied Psycholinguistics, 32(1), 221-241. https://doi.org/10.1017/S0142716410000354 
Bulté, B., \& Housen, A. (2018). Syntactic complexity in L2 writing: Individual pathways and emerging group trends. International Journal of Applied Linguistics, 28(1), 147-164. https://doi.org/10.1111/ijal.12196

Bulté, B., \& Housen, A. (2019). Beginning L2 complexity development in CLIL and non-CLIL secondary education. Instructed Second Language Acquisition, 3(2), 153-180. https://doi.org/10.1558/isla.38247

Cameron-Faulkner, T., Lieven, E., \& Tomasello, M. (2003). A construction based analysis of child directed speech. Cognitive Science, 27(6), 843-873. https://doi.org/10.1207/s15516709cog2706_2

Cameron-Faulkner, T., \& Noble, C. (2013). A comparison of book text and child directed speech. First Language, 33(3), 268-279. https://doi.org/10.1177/0142723713487613

Cartmill, E., Armstrong, B. F., Gleitman, L. R., Goldin-Meadows, S., Medinac, T. N., \& Trueswell, J. C. (2013). Quality of early parent input predicts child vocabulary 3 years later. Proceedings of the National Academy of Sciences, 110(28), 11278-11283. https://doi.org/10.1073/pnas.1309518110

Chang, Y. N., \& Monaghan, P. (2019). Quantity and diversity of preliteracy language exposure both affect literacy development: Evidence from a computational model of reading. Scientific Studies of Reading, 23 (3), 235-253. https://doi.org/10.1080/10888438.2018.1529177

Charniak, E. (2000). A maximum-entropy-inspired parser. In 1st Meeting of the North American Chapter of the Association for Computational Linguistics, 132-139. https://www.aclweb.org/anthology/A00-2018

Cohen, J. (1988). Statistical power analysis for the behavioral sciences. Routledge.

Crossley, S. A., \& McNamara, D. S. (2014). Does writing development equal writing quality? A computational investigation of syntactic complexity in L2 learners. Journal of Second Language Writing, 26, 66-79. https://doi.org/10.1016/j.jslw.2014.09.006

Department for Education (2017). Statutory framework for the early years foundation stage: Setting the standards for learning, development and care for children from birth to five. https://www.foundationyear s.org.uk/files/2017/03/EYFS_STATUTORY_FRAMEWORK_2017.pdf

Department for Education (2019). Schools, pupils and their characteristics: January 2019. https://assets.pu blishing.service.gov.uk/government/uploads/system/uploads/attachment_data/

file/812539/Schools_Pupils_and_their_Characteristics_2019_Main_Text.pdf

Department of Homeland Security (2018). Yearbook of immigration statistics. https://www.dhs.gov/ immigration-statistics/yearbook/2018, downloaded 05/02/20

Dickinson, D. K., \& Porche, M. V. (2011). Relation between language experiences in preschool classrooms and children's kindergarten and fourth-grade language and reading abilities. Child Development, 82(3), 870-886. https://doi.org/10.1111/j.1467-8624.2011.01576.x

Dickinson, D. K., \& Smith, M. W. (1994). Long-term effects of preschool teachers' book readings on lowincome children's vocabulary and story comprehension. Reading Research Quarterly, 29(2), 104-122. https://doi.org/10.2307/747807

Eurostat (2018). People in the EU: Who are we and how do we live? https://ec.europa.eu/eurostat/statisticsexplained/index.php?title=People_in_the_EU_-_who_are_we_and_how_do_we_live, downloaded 05/02/20

Frost, R. L., Monaghan, P., \& Christiansen, M. H. (2019). Mark my words: High frequency marker words impact early stages of language learning. Journal of Experimental Psychology: Learning, Memory, and Cognition, 45(10), 1883. https://doi.org/10.1037/xlm0000683

Gampe, A., Liebal, K., \& Tomasello, M. (2012). Eighteen-month-olds learn novel words through overhearing. First Language, 32(3), 385-397. https://doi.org/10.1177/0142723711433584

Giles, H., Coupland, N., \& Coupland, J. (1991). Accommodation theory: Communication, context, and consequence. In H. Giles, J. Coupland \& N. Coupland (eds.), Studies in emotion and social interaction. Contexts of accommodation: Developments in applied sociolinguistics (1-68). Cambridge University Press. https://doi.org/10.1017/CBO9780511663673.001

Golinkoff, R. M., Mervis, C. B., \& Hirsh-Pasek, K. (1994). Early object labels: The case for a developmental lexical principles framework. Journal of Child Language, 21(1), 125-155. https://doi.org/10.1017/ S0305000900008692

Guerrero, M. D. (2004). Acquiring academic English in one year: An unlikely proposition for English language learners. Urban Education, 39(2), 172-199. https://doi.org/10.1177/0042085903260915

Hart, B., \& Risley, T. (1995). Meaningful differences in the everyday experience of young American children. Baltimore, MD: Paul H. Brookes.

Hayes, D. P., \& Ahrens, M. G. (1988). Vocabulary simplification for children: A special case of 'motherese'? Journal of Child Language, 15(2), 395-410. https://doi.org/10.1017/S0305000900012411 
Hindman, A. H., Wasik, B. A., \& Snell, E. K. (2016). Closing the 30 million word gap: Next steps in designing research to inform practice. Child Development Perspectives, 10(2), 134-139. https:// doi.org/10.1111/cdep.12177

Hoff, E. (2006). How social contexts support and shape language development. Developmental Review, 26(1), 55-88. https://doi.org/10.1016/j.dr.2005.11.002

Hutchinson, J. (2018). Educational outcomes of children with English as an additional language. The Bell Foundation. https://epi.org.uk/wp-content/uploads/2018/02/EAL_Educational-Outcomes_EPI-1.pdf

Huttenlocher, J., Haight, W., Bryk, A., Seltzer, M., \& Lyons, T. (1991). Early vocabulary growth relation to language input and gender. Developmental Psychology, 27(2), 236-248. https://doi.org/10.1037/00121649.27.2.236

Huttenlocher, J., Vasilyeva, M., Cymerman, E., \& Levine, S. (2002). Language input and child syntax. Cognitive Psychology, 45(3), 337-374. https://doi.org/10.1019/S0010-0285)02)00500-5

Huttenlocher, J., Waterfall, H., Vasilyeva, M., Vevea, J., \& Hedges, L. V. (2010). Sources of variability in children's language growth. Cognitive Psychology, 61(4), 343-365. https://doi.org/10.1016/j.cogp sych.2010.08.002

Jiang, J. (2007). Linear and generalized linear mixed models and their applications. Springer.

Langeloo, A., Mascareño Lara, M., Deunk, M. I., Klitzing, N. F., \& Strijbos, J. W. (2019). A systematic review of teacher-child interactions with multilingual young children. Review of Educational Research, 89 (4), 536-568. https://doi.org/10.3102/0034654319855619

Lara-Alecio, R., Tong, F., Irby, B. J., \& Mathes, P. (2009). Teachers' pedagogical differences during ESL block among bilingual and English-immersion kindergarten classrooms in a randomized trial study. Bilingual Research Journal, 32(1), 77-100. https://doi.org/10.1080/15235880902965938

Long, M. H. (1983). Linguistic and conversational adjustments to non-native speakers. Studies in Second Language Acquisition, 5(2), 177-193. https://doi.org/10.1017/S0272263100004848

Lu, X. (2010). Automatic analysis of syntactic complexity in second language writing. International Journal of Corpus Linguistics, 15(4), 474-496. https://doi.org/10.1075/ijcl.15.4.02lu

MacWhinney, B. (2000). The CHILDES Project: Tools for analyzing talk ( $3^{\text {rd }}$ ed.). Mahwah, NJ: Lawrence Erlbaum Associates.

Markman, E. M. (1994). Constraints on word meaning in early language acquisition. Lingua, 92, 199-227. https://doi.org/10.1016/0024-3841(94)90342-5

Mashburn, A. J., Justice, L. M., Downer, J. T., \& Pianta, R. C. (2009). Peer effects on children's language achievement during pre-kindergarten. Child Development, 80(3), 686-702. https://doi.org/10.1111/ j.1467-8624.2009.01291.x

McCartney, K. (1984). Effect of quality of day care environment on children's language development. Developmental Psychology, 20(2), 244-260. https://doi.org/10.1037/0012-1649.20.2.244

McNamara, D. S., Graesser, A. C., McCarthy, P. M., \& Cai, Z. (2014). Automated evaluation of text and discourse with Coh-Metrix. Cambridge University Press.

Meurers, D. (2012). Natural language processing and language learning. In C. A. Chapelle (ed.), Encyclopedia of applied linguistics (pp. 4193-4205). Wiley.

Meurers, D., \& Dickinson, M. (2017). Evidence and interpretation in language learning research: Opportunities for collaboration with computational linguistics. Language Learning, 67(S1), 66-95. https:// doi.org/10.1111/lang.12233

Monaghan, P. J., \& Rowland, C. F. (2017). Combining language corpora with experimental and computational approaches for language acquisition research. Language Learning, 67(S1), 14-39. https:// doi.org/10.1111/lang.12221

National Institute of Child Health and Human Development Early Child Care Research Network. (2000). The relation of child care to cognitive and language development. Child Development, 71(4), 960-980. https://www.jstor.org/stable/1132337

Newman, R. S., Rowe, M. L., \& Ratner, N. B. (2016). Input and uptake at 7 months predicts toddler vocabulary: the role of child-directed speech and infant processing skills in language development. Journal of Child Language, 43(5), 1158-1173. https://doi.org/10.1017/S0305000915000446

Office for National Statistics. (2017). Migration statistics quarterly report: May 2017. https://www.ons.go v.uk/peoplepopulationandcommunity/populationandmigration/internationalmigration/bulletins/migra tionstatisticsquarterlyreport/may2017 
Palermo, F., Mikulski, A. M., Fabes, R. A., Hanish, L. D., Martin, C. L., \& Stargel, L. E. (2014). English exposure in the home and classroom: Predictions to Spanish-speaking preschoolers' English vocabulary skills. Applied Psycholinguistics, 35(6), 1163-1187. https://doi.org/10.1017/S0142716412000732

Paradis, J. (2011). Individual differences in child English second language acquisition: Comparing childinternal and child-external factors. Linguistic Approaches to Bilingualism, 1(3), 213-237. https:// doi.org/10.1075/lab.1.3.01par

Pickering, M. J., \& Garrod, S. (2013). An integrated theory of language production and comprehension. Behavioral and Brain Sciences, 36(4), 329-347. https://doi.org/10.1017/S0140525X12001495

Ping, M. T. (2014). Group interactions in dialogic book reading activities as a language learning context in preschool. Learning, Culture and Social Interaction, 3(2), 146-158. https://doi.org/10.1016/ j.lcsi.2014.03.001

R Core Team (2021). R: A language and environment for statistical computing. R Foundation for Statistical Computing, Vienna, Austria. https://www.R-project.org/

Reardon, S. F. (2013). The widening income achievement gap. Educational Leadership, 70(8), 10-16. http:// www.ascd.org/publications/educational-leadership/may13/vol70/num08/The-Widening-IncomeAchievement-Gap.aspx

Richards, B. J. (1987). Type/token ratios: What do they really tell us? Journal of Child Language, 14(2), 201-209. https://doi.org/10.1017/S0305000900012885

Rowe, M. L. (2012). A longitudinal investigation of the role of quantity and quality of child-directed speech in vocabulary development. Child Development, 83(5), 1762-1774. https://doi.org/10.1111/j.14678624.2012.01805.x

Rowe, M. L., Leech, K. A., \& Cabrera, N. (2016). Going beyond input quantity: Wh-questions matter for toddlers' language and cognitive development. Cognitive Science, 41(S1), 162-179. https:// doi.org/10.1111/cogs.12349

Rowe, M. L., \& Zuckerman, B. (2016). Word gap redux: Developmental sequence and quality. JAMA Pediatrics, 170(9), 827-828. https://doi.org/10.1001/jamapediatrics.2016.1360

Snow, C. E. (1990). The development of definitional skill. Journal of Child Language, 17(3), 697-710. https:// doi.org/10.1017/s0305000900010953

Snow, C. E., Burns, S., \& Griffin, P. (1998). Preventing reading difficulties in young children. National Academy of Sciences.

Spoonley, P. (2013). New diversity, old anxieties in New Zealand: The complex identity politics and engagement of a settler society. Ethnic and Racial Studies, 38(4), 650-661. https:// doi.org/10.1080/01419870.2015.980292

Stockman, I. J. (2010). Listener reliability in assigning utterance boundaries in children's spontaneous speech. Applied Psycholinguistics, 31(3), 363. https://doi.org/10.1017/S0142716410000032

Street, R. L., \& Giles, H. (1982). Speech accommodation theory: A social cognitive approach to language and speech behavior. In M. E. Roloff \& C. R. Berger (eds.), Social cognition and communication (pp. 193-226). Sage.

Tamis-LeMonda, C. S., Bornstein, M. H., \& Baumwell, L. (2001). Maternal responsiveness and children's achievement of language milestones. Child Development, 72(3), 748-767. https://doi.org/10.1111/14678624.00313

Tamis-LeMonda, C. S., Bornstein, M. H., Baumwell, L., \& Damast, A. M. (1996). Responsive parenting in the second year: Specific influences on children's language and play. Infant and Child Development, 5(4), 173-183. https://doi.org/10.1002/(SICI)1099-0917(199612)5:4<173::AID-EDP131>3.0.CO;2-V

Tamis-LeMonda, C. S., Custode, S., Kuchirko, Y., Escobar, K., \& Lo, T. (2018). Routine language: Speech directed to infants during home activities. Child Development, 90(6), 2135-2152. https://doi.org/10.1111/ cdev.13089

Unsworth, S. (2016a). Quantity and quality of language input in bilingual language development. In E. Nicoladis \& S. Montanari (eds.), Lifespan perspectives on bilingualism (103-121). American Psychological Association. https://doi.org/10.1037/14939-007

Unsworth, S. (2016b). Early child L2 acquisition: Age or input effects? Neither, or both? Journal of Child Language, 43(3), 603-634. https://doi:10.1017/S030500091500080X

Unsworth, S., Brouwer, S., de Bree, E., \& Verhagen, J. (2019). Predicting bilingual preschoolers' patterns of language development: degree of non-native input matters. Applied Psycholinguistics, 40(5), 1189-1219. https://doi.org/10.1017/S0142716419000225 
van Hout, R., \& Vermeer, A. (2007). Comparing measures of lexical richness. In H. Daller, J. Milton \& J. Treffers-Daller (eds.), Modelling and assessing vocabulary knowledge (pp. 93-115). Benjamins.

Vertovec, S. (2007). Super-diversity and its implications. Ethnic and Racial Studies, 30(6), 1024-1054. https://doi.org/10.1080/01419870701599465

von Hippel, P., Workman, J., \& Downey, D. B. (2017). Inequality in reading and math skills comes mainly from early childhood: A replication, and partial correction, of 'Are schools the great equalizer?'. Sociology of Education, 91(4), 323-357. https://doi.org/10.2139/ssrn.3036094

Wiig, E., Secord, W. A., \& Semel, E. (2004). The Clinical Evaluation of Language Fundamentals - Preschool $\left(2^{\text {nd }}\right.$ ed.). Harcourt Assessment.

Wiley, T. G. (2017). Diversity, super-diversity, and monolingual language ideology in the United States. Review of Research in Education, 38(1), 1-32. https://doi.org/10.3102/0091732X13511047

Youmans, G. (1990). Measuring lexical style and competence: The type-token vocabulary curve. Style, 24(4), 584-599. https://www.jstor.org/stable/42946163 


\section{Appendix A}

Further details on the fixed effect of language group in the LMEs of all identified linguistic features of preschool teacher talk in the utterances directed at the Monolingual English and EAL groups

\begin{tabular}{|c|c|c|c|c|}
\hline \multirow[b]{2}{*}{ Linguistic feature } & \multirow[b]{2}{*}{$\beta$} & \multirow[b]{2}{*}{$S E$} & \multicolumn{2}{|c|}{ Wald confidence intervals } \\
\hline & & & $2.50 \%$ & $97.50 \%$ \\
\hline \multicolumn{5}{|l|}{ Quantity } \\
\hline Number of word types & -25.11 & 12.37 & -49.36 & -0.86 \\
\hline Number of word tokens & -2.94 & 1.52 & -5.92 & 0.05 \\
\hline Number of utterances & -2.88 & 7.11 & -16.81 & 11.06 \\
\hline \multicolumn{5}{|l|}{ Quality } \\
\hline \multicolumn{5}{|l|}{ Lexical diversity } \\
\hline GI & -1.10 & 0.46 & -2.01 & -0.19 \\
\hline \multicolumn{5}{|c|}{ Parts of speech (density scores) } \\
\hline Adjectives & -3.28 & 3.92 & -10.96 & 4.40 \\
\hline Adverbs & 17.30 & 13.00 & -8.17 & 42.76 \\
\hline Conjunctions & -4.59 & 3.74 & -11.92 & 2.74 \\
\hline Coordinators & -0.49 & 3.70 & -7.73 & 6.76 \\
\hline Determiners & 0.01 & 8.70 & -17.04 & 17.06 \\
\hline Nouns & 23.37 & 13.98 & -4.04 & 50.77 \\
\hline Numerals & 0.75 & 0.60 & -0.42 & 1.92 \\
\hline Prepositions & -10.93 & 5.12 & -20.96 & -0.89 \\
\hline Pronouns & -7.09 & 13.47 & -33.48 & 19.30 \\
\hline Verbs & 2.68 & 11.98 & -20.81 & 26.16 \\
\hline \multicolumn{5}{|l|}{ Syntactic complexity } \\
\hline MLU & -1.41 & 0.43 & -2.25 & -0.56 \\
\hline SYNLE & -0.29 & 0.14 & -0.57 & -0.02 \\
\hline SYNNP & -0.09 & 0.05 & -0.18 & 0.01 \\
\hline SYNSTRUTt & 0.03 & 0.01 & 0.01 & 0.05 \\
\hline \multicolumn{5}{|c|}{ Syntactic patterns (density scores) } \\
\hline DRNP & 9.32 & 15.00 & -20.06 & 38.70 \\
\hline DRVP & 3.96 & 12.40 & -20.35 & 28.27 \\
\hline DRNEG & -0.21 & 0.75 & -1.67 & 1.26 \\
\hline
\end{tabular}


(Continued)

\begin{tabular}{ccccc}
\hline & & & \multicolumn{2}{c}{ Wald confidence intervals } \\
\cline { 3 - 5 } Linguistic feature & $\beta$ & SE & $2.50 \%$ & $97.50 \%$ \\
\hline Syntactic subcategories (density scores) & & & & 7.15 \\
\hline Copulas & -1.34 & 4.33 & -9.84 & 10.16 \\
\hline Demonstratives & 4.44 & 2.92 & -1.28 & 2.46 \\
\hline Interrogatives & -1.85 & 2.20 & -6.16 & 2.04 \\
\hline Relative pronouns & -0.62 & 1.36 & -3.28 & \\
\hline
\end{tabular}

Cite this article: Chan K.C.J., Monaghan P., \& Michel M. (2023). Adapting to children's individual language proficiency: An observational study of preschool teacher talk addressing monolinguals and children learning English as an additional language. Journal of Child Language 50, 365-390, https://doi.org/ $10.1017 /$ S0305000921000854 